\title{
KETAKSAMAAN CHEBYSHEV DAN PERUMUMANNYA
}

\author{
Pangeran B.H.P \\ Institut Teknologi Bandung \\ pangeranbhp@yahoo.com
}

\section{Hendra Gunawan}

Institut Teknologi Bandung

hgunawan@math.itb.ac.id

\begin{abstract}
We study Chebyshev's Inequality and example of its application on the expectation of a continuous random variable. In addition, we also discussed the inequality on determinant form.

Keywords: Chebyshev's Inequality, expectation, continuous random variable, matrix determinant
\end{abstract}

ABSTRAK. Dalam makalah ini akan dibahas mengenai Ketaksamaan Chebyshev dan contoh penggunaannya pada ekpektasi dari suatu peubah acak kontinu. Sebagai tambahan, dibahas juga ketaksamaan dalam bentuk determinan matriks.

Kata Kunci: Ketaksamaan Chebyshev, ekspektasi, peubah acak kontinu, determinan matriks

\section{PENDAHULUAN}

Misalkan $f$ terdefinisi pada suatu himpunan $H$. Kita katakana bahwa $f$ naik pada

$H$ apabila untuk setiap $x, y \in H$ dengan $x<y$ berlaku

$$
f(x) \leq f(y) .
$$

Jika ketaksamaan < berlaku, maka kita katakana bahwa $f$ naik sejati pada $H$.

Definisi serupa dapat dirumuskan untuk fungsi turun dan turun sejati pada $H$. Fungsi naik atau turun disebut fungsi monoton. 
Teorema 1.1. (Ketaksamaan Chebyshev). Jika $f, g:[a, b] \rightarrow \mathbb{R}$ adalah fungsi dengan kemonotonan yang sama maka

$$
\frac{1}{b-a} \int_{a}^{b} f(x) g(x) d x \geq\left(\frac{1}{b-a} \int_{a}^{b} f(x) d x\right)\left(\frac{1}{b-a} \int_{a}^{b} g(x) d x\right)
$$

Arah ketaksamaan dibalik bila $f, g$ fungsi dengan kemonotonan yang berbeda.

Bukti dapat dilihat pada (Niculescu dan Pecarie, 2010).

\section{PEMBAHASAN}

\subsection{Ketaksamaan Chebyshev dengan fungsi bobot}

Teorema 2.1. (Mitrinuvie, dkk., 1993). Jika $f, g:[a, b] \rightarrow \mathbb{R}$ adalah fungsi dengan kemonotonan yang sama, $p$ positif dan terintegralkan Riemann pada $[a, b]$ maka

$\int_{a}^{b} p(x) d x \int_{a}^{b} p(x) f(x) g(x) d x \geq \int_{a}^{b} p(x) f(x) d x \int_{a}^{b} p(x) g(x) d x$

Bukti analogi seperti pada (Niculescu dan Pecarie, 2010) yakni menggunakan fakta bahwa untuk setiap $x, y \in[a, b]$ berlaku

$$
p(x) p(y)(f(x)-f(y))(g(x)-g(y)) \geq 0
$$

\subsection{Ekspektasi}

Misalkan $p:[a, b] \subset \mathbb{R} \rightarrow \mathbb{R}_{+}$merupakan fungsi padat peluang dari peubah acak $X$ dan

$$
E(X):=\int_{a}^{b} x p(x) d x
$$

adalah ekpektasi dari peubah acak $X$.

\subsection{Penggunaan Ketaksamaan Chebyshev pada Ekspektasi}


Dengan menggunakan Teorema 2.1, analogikan $p(x)$ sebagai fungsi padat peluang dari suatu peubah acak kontinu $X$ karena $p:[a, b] \subset \mathbb{R} \rightarrow \mathbb{R}_{+}$dan sebagai akibat $p(x)$ merupakan fungsi padat peluang maka $\int_{a}^{b} p(x) d x=1$.

Berdasarkan (2) diperoleh

$$
E[f(X) g(X)] \geq E[f(X)] E[g(X)]
$$

Untuk $f, g:[a, b] \rightarrow \mathbb{R}$ adalah fungsi dengan kemonotonan yang sama. Seperti pada kasus sebelumnya, arah ketaksamaan dibalik bila $f, g$ fungsi dengan kemonotonan yang berbeda.

\subsection{Perumuman dengan bentuk determinan}

Sebagai langkah awal, tinjau

$$
\begin{aligned}
& (f(x)-f(y))(g(x)-g(y)) \\
= & \left|\begin{array}{cc}
1 & 1 \\
f(y) & f(x)
\end{array}\right|\left|\begin{array}{cc}
1 & 1 \\
g(y) & g(x)
\end{array}\right|
\end{aligned}
$$

Hal ini ingin mengatakan bahwa Ketaksamaan Chebyshev dapat dinyatakan dalam bentuk determinan matriks.

\section{Ketaksamaan Chebyshev dalam bentuk determinan}

Teorema 2.2. (Mitrinuvie, dkk., 1993). Jika $f_{1}, f_{2}, \ldots, f_{n}$ dan $g_{1}, g_{2}, \ldots, g_{n}$ fungsi yang terintegralkan Riemann pada $[a, b]$ dan

$$
\left|\begin{array}{ccc}
f_{1}\left(x_{1}\right) & \ldots & f_{1}\left(x_{n}\right) \\
\vdots & \ddots & \vdots \\
f_{n}\left(x_{1}\right) & \ldots & f_{n}\left(x_{n}\right)
\end{array}\right|\left|\begin{array}{ccc}
g_{1}\left(x_{1}\right) & \ldots & g_{1}\left(x_{n}\right) \\
\vdots & \ddots & \vdots \\
g_{n}\left(x_{1}\right) & \ldots & g_{n}\left(x_{n}\right)
\end{array}\right| \geq 0
$$

maka

$$
\left|\begin{array}{ccc}
\int_{a}^{b} f_{1}(x) g_{1}(x) d x & \ldots & \int_{a}^{b} f_{1}(x) g_{n}(x) d x \\
\vdots & \ddots & \vdots \\
\int_{a}^{b} f_{n}(x) g_{1}(x) d x & \ldots & \int_{a}^{b} f_{n}(x) g_{n}(x) d x
\end{array}\right| \geq 0
$$


Ide pembuktian akan dimulai dari kasus determinan matriks $2 \times 2$.

Jika $f_{i}$ dan $g_{i}$ fungsi yang terintegralkan Riemann pada $[a, b]$ dan

$$
\left|\begin{array}{ll}
f_{1}\left(x_{1}\right) & f_{1}\left(x_{2}\right) \\
f_{2}\left(x_{1}\right) & f_{2}\left(x_{2}\right)
\end{array}\right|\left|\begin{array}{ll}
g_{1}\left(x_{1}\right) & g_{1}\left(x_{2}\right) \\
g_{2}\left(x_{1}\right) & g_{2}\left(x_{2}\right)
\end{array}\right| \geq 0
$$

dengan $x_{1}, x_{2} \in[a, b]$ maka

$$
\left|\begin{array}{ll}
\int_{a}^{b} f_{1}(x) g_{1}(x) d x & \int_{a}^{b} f_{1}(x) g_{2}(x) d x \\
\int_{a}^{b} f_{2}(x) g_{1}(x) d x & \int_{a}^{b} f_{2}(x) g_{2}(x) d x
\end{array}\right| \geq 0
$$

Bukti.

$$
\begin{aligned}
& \left|\begin{array}{ll}
\int_{a}^{b} f_{1}(x) g_{1}(x) d x & \int_{a}^{b} f_{1}(x) g_{2}(x) d x \\
\int_{a}^{b} f_{2}(x) g_{1}(x) d x & \int_{a}^{b} f_{2}(x) g_{2}(x) d x
\end{array}\right| \\
& =\int_{a}^{b} f_{1}\left(x_{1}\right)\left|\begin{array}{cc}
g_{1}\left(x_{1}\right) & g_{2}\left(x_{1}\right) \\
\int_{a}^{b} f_{2}\left(x_{2}\right) g_{1}\left(x_{2}\right) d x & \int_{a}^{b} f_{2}\left(x_{2}\right) g_{2}\left(x_{2}\right) d x
\end{array}\right| d x_{1} \\
& =\int_{a}^{b} \int_{a}^{b} f_{1}\left(x_{1}\right) f_{2}\left(x_{2}\right)\left|\begin{array}{ll}
g_{1}\left(x_{1}\right) & g_{2}\left(x_{1}\right) \\
g_{1}\left(x_{2}\right) & g_{2}\left(x_{2}\right)
\end{array}\right| d x_{1} d x_{2} \\
& =\int_{a}^{b} \int_{a}^{b} f_{1}\left(x_{1}\right) f_{2}\left(x_{2}\right)\left|\begin{array}{ll}
g_{1}\left(x_{1}\right) & g_{1}\left(x_{2}\right) \\
g_{2}\left(x_{1}\right) & g_{2}\left(x_{2}\right)
\end{array}\right| d x_{1} d x_{2}
\end{aligned}
$$

Dilain pihak,

$$
\begin{aligned}
& \left|\begin{array}{lc}
\int_{a}^{b} f_{1}(x) g_{1}(x) d x & \int_{a}^{b} f_{1}(x) g_{2}(x) d x \\
\int_{a}^{b} f_{2}(x) g_{1}(x) d x & \int_{a}^{b} f_{2}(x) g_{2}(x) d x
\end{array}\right| \\
& =\int_{a}^{b} f_{2}\left(x_{1}\right)\left|\begin{array}{cc}
\int_{a}^{b} f_{1}\left(x_{2}\right) g_{1}\left(x_{2}\right) d x & \int_{a}^{b} f_{1}\left(x_{2}\right) g_{2}\left(x_{2}\right) d x \\
g_{1}\left(x_{1}\right) & g_{2}\left(x_{1}\right)
\end{array}\right| d x_{1} \\
& =\int_{a}^{b} \int_{a}^{b} f_{2}\left(x_{1}\right) f_{1}\left(x_{2}\right)\left|\begin{array}{ll}
g_{1}\left(x_{2}\right) & g_{2}\left(x_{2}\right) \\
g_{1}\left(x_{1}\right) & g_{2}\left(x_{1}\right)
\end{array}\right| d x_{1} d x_{2} \\
& =\int_{a}^{b} \int_{a}^{b}-f_{2}\left(x_{1}\right) f_{1}\left(x_{2}\right)\left|\begin{array}{ll}
g_{1}\left(x_{1}\right) & g_{1}\left(x_{2}\right) \\
g_{2}\left(x_{1}\right) & g_{2}\left(x_{2}\right)
\end{array}\right| d x_{1} d x_{2} \quad \text { (**) }
\end{aligned}
$$


maka dari $(*)$ dan $(* *)$ didapat

$$
\begin{aligned}
& \left|\begin{array}{ll}
\int_{a}^{b} f_{1}(x) g_{1}(x) d x & \int_{a}^{b} f_{1}(x) g_{2}(x) d x \\
\int_{a}^{b} f_{2}(x) g_{1}(x) d x & \int_{a}^{b} f_{2}(x) g_{2}(x) d x
\end{array}\right| \\
= & \frac{1}{2} \int_{a}^{b} \int_{a}^{b}\left(f_{1}\left(x_{1}\right) f_{2}\left(x_{2}\right)-f_{2}\left(x_{1}\right) f_{1}\left(x_{2}\right)\right)\left|\begin{array}{ll}
g_{1}\left(x_{2}\right) & g_{2}\left(x_{2}\right) \\
g_{1}\left(x_{1}\right) & g_{2}\left(x_{1}\right)
\end{array}\right| d x_{1} d x_{2} \\
= & \frac{1}{2} \int_{a}^{b} \int_{a}^{b}\left|\begin{array}{ll}
f_{1}\left(x_{1}\right) & f_{1}\left(x_{2}\right) \\
f_{2}\left(x_{1}\right) & f_{2}\left(x_{2}\right)
\end{array}\right|\left|\begin{array}{ll}
g_{1}\left(x_{2}\right) & g_{2}\left(x_{2}\right) \\
g_{1}\left(x_{1}\right) & g_{2}\left(x_{1}\right)
\end{array}\right| d x_{1} d x_{2} \geq 0
\end{aligned}
$$

berdasarkan sifat positif integral.

Lalu dengan cara yang sama untuk matriks

$$
\begin{aligned}
& \left|\begin{array}{ccc}
\int_{a}^{b} f_{1}(x) g_{1}(x) d x & \ldots & \int_{a}^{b} f_{1}(x) g_{n}(x) d x \\
\vdots & \ddots & \vdots \\
\int_{a}^{b} f_{n}(x) g_{1}(x) d x & \ldots & \int_{a}^{b} f_{n}(x) g_{n}(x) d x
\end{array}\right| \\
& =\frac{1}{n !} \int_{a}^{b} \ldots \int_{a}^{b}\left|\begin{array}{ccc}
f_{1}\left(x_{1}\right) & \ldots & f_{1}\left(x_{n}\right) \\
\vdots & \ddots & \vdots \\
f_{n}\left(x_{1}\right) & \ldots & f_{n}\left(x_{n}\right)
\end{array}\right|\left|\begin{array}{ccc}
g_{1}\left(x_{1}\right) & \ldots & g_{1}\left(x_{n}\right) \\
\vdots & \ddots & \vdots \\
g_{n}\left(x_{1}\right) & \ldots & g_{n}\left(x_{n}\right)
\end{array}\right| d x_{1} \ldots d x_{n} \geq 0 .
\end{aligned}
$$

Hal ini dikarenakan ada $n$ ! cara dalam pengambilan $f_{i}$.

\section{KESIMPULAN DAN SARAN}

Ketaksamaan Chebyshev merupakan ketaksamaan yang membandingkan perkalian dua integral fungsi dengan integral dari perkalian dua fungsi dengan syarat fungsi tersebut merupakan fungsi monoton. Ketaksamaan Chebyshev dengan fungsi bobot dapat digunakan dalam ekspektasi suatu peubah acak kontinu dengan fungsi bobotnya berperan sebagai fungsi padat peluang.

Lebih lanjut, syarat Ketaksamaan Chebyshev dapat diperlemah yakni dengan menyatakan ketaksamaan dalam bentuk determinan. 


\section{DAFTAR PUSTAKA}

Cerone P. dan Dragomir S.S, (2011), Mathematical Inequalities: A Perspective , Taylor and Francis Group, LLC.

Mitrinovic D. S. , Pecaric J. E. dan Fink A. M. , (1993), Classical and New Inequalities in Analysis, Kluwer, Dordrecht, 1993.

Niculescu C. P. dan Pecaric J. E., (2010), The equivalence of Chebyshev's inequality with the Hermite-Hadamard inequality. Math. Reports, 12 (62), No. 2, pp. 145156.

Walpole R.E., (2007), Probability \& Statistics for Engineers \& Scientists $8^{\text {th }}$ edition. Pearson Education International. 